\title{
Attitudes of Hotel Managers Towards EC in South Africa
}

\author{
Nomsa Mndzebele
}

\begin{abstract}
Advances in Information Communication Technology (ICT) have changed the way of doing business in many industries, including tourism and hospitality. Much has been written about the importance of ICT particularly on how the use of the ICT in the lodging industry is growing exponentially and that this enables hotels to reconsider the way they are doing business. As a result, more emphasis is now on how to change the attitude of hotel managers towards adopting ICT to enhance hotel performance. Educating the manager about affordances of ICT determines whether or not the hotel will benefit from the new technology. The author examined the relationship between managers' attitudes and the extent of electronic commerce (EC) adoption. The paper examines the perceptions of 332 South African managers within the South African hotel industry. A quantitative research design was used through a questionnaire to collect data from the managers. The research highlights the importance of changing the managers' attitude for technology to be accepted.
\end{abstract}

Index Terms-Attitude, electronic commerce, information technology and adoption.

\section{INTRODUCTION}

The hotel directions concerning the acceptance of new technologies, is subject to a manager's perception of the direction and speed of changes in the market, irrespective of how accurate these observations may be. The role played by senior managers has been seen as being the most significant contributing factor to the behaviour of organisations in terms of their adopting or ignoring new technologies. [1] have found that when managers consider technologies to be of strategic significance, a realistic approach is taken to analyse these new technologies for strategic purposes. Because of the interest of the manager, it is easier to obtain the necessary capital, human resources and any other related internal resources that are necessary to adopt the technology [2], [3]. However, if managers do not perceive any benefits to technology, IT will only play a peripheral role in that hotel. Not only does this paper probe what determines the predisposition for some managers to have a positive attitude towards adoption of EC but also the extent to which the managers' attitudes affect the possibility of an organisation adopting electronic commerce (EC). [4] have developed a theoretical foundation for answering the above questions. The key success factors include to identify the determinants of adoption and then to investigate how managerial attitudes affect the adoption.

However, there is lack of empirical studies that provide evidence on how managerial attitudes mediate the above mentioned relationship between adoption and the extent of adoption. In addition, there is very little information about EC on the African continent, with the exception of South Africa [5]-[6]. EC in Ethiopia is still at its infancy [7], with only a few organizations using ICT in their business transactions. South Africa is considered as one of the top developing countries in the world in the sense that ICT people trained in South Africa are lured to other countries [8]. South Africa has a diversified economy, which creates a culture that encourages the development of skills in Information Communication Technology (ICT). It is therefore in the best position among all the African countries to take the most advantage of ICT. The same study by [8] reported that international survey organizations predicted that online shoppers in South Africa would spend US\$443 million in 2009 on internet generated purchases and business to business EC would reach almost US\$ 620 million in the same year. In 2003, 35\% of retailers in South Africa were using the Internet to trade online and the total amount spent on shopping online that year was 341 million [9].

Previous studies clearly show that there is a significant association between support for ICT by management and the acceptance of technology within a hotel. The following studies do not only show the association between support from management and technology but they also show that a manager's attitude is important if adequate resources are to be acquired for adopting new technologies: [10]-[13], [1] have also found that those organisations whose managers perceive ICT to be beneficial, compatible and relatively easy to use are relatively more likely to adopt ICT. There is no doubt that managers can positively or negatively influence the adoption of technology in an organisation. As expected, it is important to train hotel managers (i.e. provide them with the necessary information about ICT) in order to change their attitude towards new technologies. As [14]-[15] have also found, the attitude of a general manager can be influenced by his/her level of education and training. Therefore, with appropriate training the acceptance of technology would be encouraged.

The purpose of this study is to explore the experiences of the participants in relation to the introduction of new information technology. The intention is to identify the unique circumstances that may cause users to either accept or reject new information technology. Based on the literature review, it has been suggested that users' resistance to ICT could be the result of, for example, the ease of use of new technology, its usefulness, and bad experiences from previous attempts to use new technology [13], [16].

\section{Methodology}

A quantitative research design has been used for the study.

Nomsa Mndzebele is with the Faculty of Commerce, University of Swaziland, Kwaluseni, Swaziland (e-mail: nomsa@uniswa.sz). 
For the data collection process, a correlational and descriptive research survey has been used. Correlation was chosen because the researcher wanted to find out if there is a relationship between the manager's attitude and the dependent variable.

In the literature reviewed, the researcher identified attitudes as a success factor that was perceived as being of importance with regard to EC adoption by hotels in South Africa. To answer the research question, on the manager's attitude, and the extent of EC adoption, which includes EC acceptance of Business to Business (B2B) inbound communication, EC acceptance of B2B outbound communication, EC acceptance of Business to Consumer (B2C) inbound communication, and EC acceptance of B2C order taking. The manager's attitude constitutes the independent variable and the extent of EC adoption constitutes the dependent variables.

The hotels were drawn from the databases of three major groups of hotels, as suggested by the South African Tourism office. These three groups are: (1) the Tourism Grading Council hotel listing, (2) the Tshwane accommodation listing and (3) the AA travel accommodation listing. The researcher used systematic sampling from each of the three groups identified by the [17] so that each group would be represented. [18] have all suggested that if a population was about 1,500 , a sample size of 300 would be acceptable. A total of 332 questionnaires were collected. To answer the research question, the Pearson and Spearman correlations were used.

\section{RESUltS AND DISCUSSIONS}

A composite of twelve questions on the questionnaire was used to measure the relationship between management attitudes and the extent of EC adoption. The descriptive statistics shows a mean score of 3.005. Most of the managers seemed to have a positive attitude towards EC adoption as illustrated in Table I below which indicates the four categories of EC adoption and the strength of the relationship between the extent of EC adoption on managers' attitudes. Cronbach's alpha value for this set of questions is 0.583 . To examine the association between the managers' attitudes and the extent of EC adoption, Pearson $r$ correlation analysis was applied. Only two of the dependent variables show a positive relationship with the extent of EC adoption.

TABLE I: CORRELATION ANALYSIS OF MANAGEMENT ATTITUDES TO EC

\begin{tabular}{|l|l|l|}
\hline \multicolumn{3}{|c}{ ADOPTION } \\
\hline B2C outbound communication & Correlation & Sig. \\
\hline B2C order taking & $.205^{* *}$ & .000 \\
\hline B2B inbound Communication & .072 & .192 \\
\hline B2B outbound communication & -.014 & .803 \\
\hline
\end{tabular}

* Correlation is significant at the 0.05 level (2-tailed).

** Correlation is significant at the 0.01 level (2-tailed).

B2C outbound communication: The statistical significance of managers' attitudes in B2C outbound communication is at the significant level of 0.01 . Between the managers' attitudes and the extent of EC adoption on B2C outbound communication, the correlation coefficient $r$ is 0.205. The effect is positive, with a medium effect size.

B2B outbound communication: The statistical significance of managers' attitude in B2B outbound communication is at the significant level of .01. Between the managers' attitudes and the extent of EC adoption on B2B outbound communication, the correlation coefficient $r$ is 0.234. The effect is positive, and the strength of the relationship is large.

Of the twelve questions that are used, the following questions are significant; Q2 (involved in adoption), Q.7 (receptive to new ideas) and Q.12 (must come up with original ideas).

The question that is significant in a number of the dependent variables is Q.7"I am receptive to new ideas", which is important in the hotel industry. To achieve competitive advantage, a manager has to keep up with what is happening and be ready for change; otherwise the business will lag behind competitors. However, [3], [13] argue that the hotel industry has not been improving in technology because the managers are not receptive to new ideas. Yet not only does the manager have to be receptive to what the customer wants but to also provide products or services with which the customer is happy. The manager has to find out what it is that the customers want and what is happening in the industry. As expected, the hotel manager has to be receptive to new ideas coming from the hotel's suppliers too. A manager can learn from suppliers what other hotels are offering, and obtain information on the trends of EC within the hotel business.

It is important that managers be involved in the adoption of B2C outbound communication. If managers are not involved, their businesses will be less competitive because they will not keep up with innovations and new trends within such a dynamic hotel industry [19]. Managers may resist new technologies because of a limited understanding of what the new technologies offer, while the hotel's consumers will be asking for the latest innovations of which the manager is not aware of, and will fail to respond in time because s/he is not sure of what is being asked. In a study conducted by [19] and [20], hotel managers mentioned that they realise that they have to change their attitudes towards adopting new technologies and be willing to learn how to maintain them.

In response to the Q.12 statement that managers must come up with their own original ideas, the main finding was that managers have to be innovative. If a manager has to develop the ICT applications for the hotel, then that manager has to decide what is needed. In this way the manager is being innovative in order to meet the demands of the customers of that hotel. A manager who is not innovative will always lag behind in the adoption of new technologies. Table I show that there is no correlation between B2C order taking and B2C inbound communication and the manager's attitude in the hotel industry. There is a positive correlation with B2C outbound and B2B outbound and the manager's attitude. In Table II, multiple regression analysis, however, $p$ was positive in all the dependent variables.

Therefore, the manager should try to be innovative in order to make the life of the hotel staff and its clients easier and more pleasant.

On the extent of the overall adoption prediction, all the 
dependent variables have a positive influence on the extent of EC adoption on management attitudes prediction. The dependent variables significantly contributed to the model for predicting the extent of EC adoption on management attitudes prediction.

TABLE II: MULTIPLE REGRESSION ANALYSIS ON THE EXTENT OF EC ADOPTION

\begin{tabular}{|l|l|l|l|l|}
\hline Equation & RMSE & R-sq & F & P \\
\hline $\begin{array}{l}\text { B2C outbound } \\
\text { communication }\end{array}$ & 1.045 & .192 & 2.535 & .001 \\
\hline B2C order taking & .849 & .254 & 3.652 & .000 \\
\hline $\begin{array}{l}\text { B2B inbound } \\
\text { communication }\end{array}$ & 1.236 & .304 & 4.677 & .000 \\
\hline $\begin{array}{l}\text { B2B outbound } \\
\text { communication }\end{array}$ & 1.264 & .314 & 4.909 & .000 \\
\hline
\end{tabular}

RMSE $=$ Root Mean Square Error

The $\mathrm{R}^{2}$ overall variation is explained by the independent variables in the model. In the case of B2B outbound communication, the value is 0.31 , which means that $31 \%$ of the variance in the overall extent of EC adoption on management attitudes prediction was explained by this model. According to [17], the effect size of this model is large.

\section{CONCLUSION}

Finally, from the responses to the questions asked, it came out clearly that managers have to be involved in the adoption of EC to know what is happening in the industry. The manager has to be receptive to new ideas, especially those that come from the customers. In this way hotel managers will meet the needs of the client. The manager has to be innovative and forward thinking. The study also generated compelling evidence about the following:

1) The manager's attitude toward EC has a significantly positive relationship with the extent of EC adoption in B2C communication.

2) Manager's attitude towards EC adoption is an important success factor. Attitude can be explained as the extent of an individual's favourable or unfavourable reactions toward a given behaviour. The correlation analysis indicates that there is a positive association between the extent of EC in both B2C outbound communications and B2B outbound communication and a manager's attitude [11]. Of the managers surveyed from the South African hotel industry, $50 \%$ were neutral in their attitude towards EC. $p=.000$ on both variables, at a significant level of 0.01 , and the direction of the effect is positive, with a small effect size.

As a result, the findings of this study are consistent with the findings of other studies, which state that there is a positive relationship between both $\mathrm{B} 2 \mathrm{C}$ outbound communication and $\mathrm{B} 2 \mathrm{~B}$ outbound communication and manager's attitude. For example, of the managers surveyed, $50 \%$ showed that they did not perceive attitude to be a predictor of EC. Yet the findings confirm the assertion that when technologies are considered by managers to be of strategic significance, a realistic approach is taken to analyse new technologies, and it is easier to obtain the necessary resources if management agrees.

Using multiple regression analysis and correlation analysis, the variable of manager's attitudes towards EC adoption is influential on the extent of EC adoption. For suppliers who targeted their marketing at EC businesses with the hotels, the researcher suggests that these suppliers should take steps to create EC awareness for hotels with lesser extent of EC adoption. Therefore, managers may develop more positive attitudes towards EC adoption when they understand its potential benefits, and would be more willing to adopt EC. As the managers' attitudes become positive, they are likely to be more receptive to new ideas of adoption. Similarly, suppliers can become equally innovative by developing new production processes, new markets, such as innovative products and imaginative advertising campaigns.

\section{REFERENCES}

[1] A. H. Seyal and M. N. A. Rahman, "A preliminary Investigation of E-commerce adoption in small medium enterprises in Brunei," Journal of Global Information Technology, vol. 6, no. 2, pp. 6-26, 2003.

[2] K. Zhu and K. L. Kraemer, "Post adoption variations in usage and value of e-business by organisations: cross country evidence from the retail industry," Information Systems Research, vol. 16, no.1, pp. 61-84, 2005 .

[3] K. Zhu, "The complementary information technology infrastructure and e-commerce capability: A resource based assessment of their business value," Journal of Management Information Systems, vol. 21, no. 1, pp. 167-202, 2004.

[4] F. D. Davis, "Perceived usefulness, perceived ease of use, and user acceptance of information technology," MIS Quartely, vol. 13, no. 3, pp. 319-339, 1989

[5] A. Molla and P. Licker, "Maturation stage of e-commerce in developing countries: A survey of South african companies," Journal of IT and International Development, vol. 2, no. 1, pp. 89-98, 2004.

[6] S. Moodley, "The challenge of e-business for the South African apparel sector," Technovation, vol. 23, pp. 557-570, 2003.

[7] E. Ayalew, L. Lessa, and M. Yigzaw. (August 1-17, 2010), "E-commerce Readiness in Ethiopia: A Macro-level Assessment," presented at Americas Conference in Information Systems, [Online]. Available: http://aisel.aisnet.org/amcis2010/130.

[8] P. Esselaar and J. Miller, "Towards Electronic Commerce in Africa. A perspective from three countries," Southern African Journal of Information and Communication, vol. 2, no. 1, pp. 1-19, 2002.

[9] J. McClatchey, K. Cattell, and K. Mitchell, "The Impact of online retail grocery shopping on retail space: a Cape Town case study," Emerald, vol. 25 , no. 3/4, pp. 115-126, 2007.

[10] S. Sahadev, and N. Islam, "Why hotels adopt ICTs: a study on the ICT adoption propensity of hotels in Thailand," International Journal of Contemporary Hospitality Management, vol. 17, no. 4/4, pp. 391-400, 2005.

[11] T. Lam, V. Cho, and H. Qu, "A study of hotel employee behavioral intentions towards adoption of information technology," International Journal of Hospitality Management, vol. 26, no.1, pp. 49-65, 2007.

[12] P. Gamble, "Attitudes to computers of managers in the hospitality industry," Behaviour and Information Technology, vol. 7, no. 3, pp. 303-321, 1998.

[13] T. Maswera, J. Edwards, and R. Dawson, "Recommendations for e-commerce systems in the tourism industry of Sub-Saharan Africa," Telematics and Informatics, vol. 26, pp. 12-19, 2009.

[14] J. L. Gibbs and K. L. Kraemer, "Cross-country investigation of the determinants of scope of e-commerce use: an institutional approach," Electronic Markets, vol. 14, no. 2, pp. 124-137, 2004.

[15] H. F. Lin and G. G. Lee, "Impact of organisational learning and knowledge management factors on e-busienss adoption," Management Decision, vol. 43, no. 2, pp. 171-188, 2005.

[16] T. Maswera, R. Dawson, and J. Edwards, "E-commerce adoption of travel and tourism organisations in South Africa, Kenya, Zimbabwe 
and Uganda," Telematics and Informatics, Elsevier, vol. 26, pp. 12-19, 2006.

[17] Tourism Satelite Accounting. (2008). The 2008 Travel \& Tourism economic research South Africa. World Travel \& Tourism Council. [Online].

Available: http://www.wttc.org/research/economic-impact-research/

[18] P. Leedy and J. E. Ormmrod, Practical Research (Planning and Design), New Jersey: Pearson Merrill Prentice Hall, vol. 9, pp. 207.

[19] S. Hawk, "Comparison of B2C e-commerce in developing countries," Electronic Commerce Research, vol. 14, no. 3, pp. 181-190, 2004.

[20] I. Hipkin and D. Bennet, "Managerial perceptions of factors influencing technology management in South Africa," Technovation, vol. 23, no. 9, pp. 719-735, 2003.
N. Mndzebele achieved his Bachelor of Commerce in Accounting in 1989 He worked in industry as Cost Accountant,. In 1992, he stated teaching at Swaziland College of Technology teaching Accounting. In 1995, he got an MBA CALPOLY in California USA and specialized in Management Information Systemsand started teaching at the University of Swaziland. He have also done some training in Entrepreneurship and Micro Financing. In 2012, he got a PHD in Information Systems at the University of KwazuluNatal South Africa. 